\title{
PREDIKSI JUMLAH KEBERANGKATAN PENUMPANG PESAWAT TERBANG MENGGUNAKAN MODEL VARIASI KALENDER DAN DETEKSI OUTLIER (Studi Kasus di Bandara Soekarno-Hatta)
}

\author{
Alvi Waldira ${ }^{1}$, Abdul Hoyyi ${ }^{2}$, Dwi Ispriyanti ${ }^{3}$ \\ 1,2,3 Departemen Statistika FSM Universitas Diponegoro \\ alviwaldira@gmail.com
}

\begin{abstract}
Transportation has a strategic role, even becoming one of the main needs of the community, especially air transportation services. A large number of passengers in air transportation always experiences a difference every month. One of the differences occurred when approaching Eid al-Fitr, which changes every year based on an Islamic calendar that is different from Masehi calendar. The lunar shift in the occurrence of Eid al-Fitr forms a pattern called calendar variation. The effects of calendar variations can be overcome by using an additional variable, such as a dummy variable, this variable which will be used in the ARIMAX model. Observation of time series is often influenced by several unexpected events such as outliers. This outlier causes the results of data analysis to be less valid. So the researchers added the detection of outliers in this study. Based on the analysis results, the ARIMA calendar variation model is obtained $(1.0,[12])$, with time variable t, dummy variable $D_{t 2}$, and the addition of one outlier. This model has a MAPE value of 0.07079609 which means this model is very good for forecasting. Forecasting results showed an increase in the number of passengers during the two months before Eid.
\end{abstract}

Keywords: Passenger, calendar variation, outlier detection

\section{PENDAHULUAN}

Penumpang transportasi udara selalu mengalami perbedaan setiap bulannya. Salah satu penyebab terjadinya lonjakan penumpang itu banyak terjadi adalah saat-saat mendekati hari raya Idul Fitri yang setiap tahunnya berubah berdasarkan Kalender Islam yang berbeda dengan Kalender Masehi. Untuk mengetahui tingkat terjadinya lonjakan penumpang yang terjadi, maka perlu dilakukan analisis time series pada data kedatangan penumpang yang ada. Perbedaan jumlah masing-masing hari berbeda dari bulan ke bulan dan tahun ke tahun, tersebut dinamakan efek variasi kalender.

Salah satu metode peramalan yang digunakan untuk menangani efek variasi kalender ini adalah model ARIMAX yang merupakan perluasan dari model ARIMA. Model ini menggunakan variabel tambahan yang diperoleh dari variasi kalender yang dijadikan sebagai variabel dummy

Pengamatan deret waktu sering kali dipengaruhi oleh beberapa peristiwa yang tidak terduga seperti perang, krisis politik atau ekonomi, bahkan kesalahan yang tidak disengaja saat merekap data. Konsekuensi dari peristiwa ini menyebabkan pengamatan yang tidak konsisten dengan data-data lainnya. Pengamatan semacam itu dinamakan outlier. Outlier menyebabkan hasil dari analisis data menjadi kurang valid sehingga sangat penting untuk melakukan deteksi dan penanganan outlier.

Berdasarkan uraian tersebut maka studi kasus pada Tugas Akhir ini adalah peramalan jumlah penumpang pesawat terbang dengan menggunakan model variasi kalender dan pendeteksian outlier. 


\section{TINJAUAN PUSTAKA}

\subsection{Model Regresi Dummy}

Variabel tak bebas (dependent variable) dipengaruhi tidak hanya oleh variabel bebas (independent variable) yang bersifat kuantitatif, tetapi juga variabel bebas yang bersifat kualitatif. Variabel kualitatif ini mengindikasikan ada tidaknya sebuah atribut. Sehingga variabel kualitatif ini perlu dikonversikan ke dalam bentuk kuantitatif sehingga dapat mengaplikasikan metode regresi. Salah satu cara mengkuantitatifkan atribut yang bersifat kualitatif tersebut yaitu membentuk variabel dummy. Variabel dummy bernilai 1 menunjukkan adanya atribut sedangkan nilai 0 menunjukkan tidak adanya atribut. Bentuk umum model regresi dummy adalah sebagai berikut:

$$
Z_{t}=\beta_{0}+\beta_{1} D_{1, t}+\beta_{2} D_{2, t}+\ldots+\beta_{(m-1)} D_{(m-1), t}+\varepsilon_{t}
$$

dimana $\beta_{0}, \beta_{1}, \beta_{2}, \ldots, \beta_{m}$ adalah koefisien parameter terkait dengan variabel dummy $D_{1, t}, D_{2, t}, \ldots, D(m-1), t$ dimana $\varepsilon_{t}$ adalah residual model regresi dummy.

Estimasi parameter dummy menggunakan metode ordinary least square (OLS). Prinsip ini meminimumkan jumlah kuadrat residual yang dihasilkan oleh model dengan syarat minimum untuk turunan pertama dari jumlah kuadrat residual terhadap $\hat{\beta}_{1}, \hat{\beta}_{2}, \ldots, \hat{\beta}_{m-1}$ disamakan nol dan turunan kedua bernilai positif atau lebih dari nol.

Semua turunan pertama dari semua parameter akan disusun sehingga diperoleh persamaan matriks:

$$
\mathbf{D}^{\prime} \mathbf{Z}=\mathbf{D}^{\prime} \mathbf{D} \widehat{\boldsymbol{\beta}}
$$

Sehingga diperoleh estimasi parameter $\widehat{\boldsymbol{\beta}}$ sebagai berikut:

$$
\widehat{\boldsymbol{\beta}}=\left(\boldsymbol{D}^{\prime} \boldsymbol{D}\right)^{-1} \boldsymbol{D}^{\prime} \boldsymbol{Z}
$$

\subsection{Analisis Time Series}

\subsubsection{Model ARIMA}

1. Proses Autoregressive tingkat p atau $A R(p)$

Menurut Wei (2006), bentuk umum dari suatu proses Autoregressive tingkat $\mathrm{p}(\mathrm{AR}(\mathrm{p}))$ adalah:

$$
Z_{t}=\phi_{1} Z_{t-1}+\phi_{2} Z_{t-2}+\cdots+\phi_{p} Z_{t-p}+a_{t}
$$

2. $\quad$ Proses Moving Average tingkat $q$ atau $M A(q)$

Menurut Wei (2006), bentuk umum dari proses Moving Average tingkat q atau proses MA (q) adalah sebagai berikut:

$$
Z_{t}=a_{t}-\theta_{1} a_{t-1}-\theta_{2} a_{t-2}-\cdots-\theta_{q} a_{t-q}
$$

3. Proses Autoregressive Moving Average atau ARMA (p,q)

Menurut Wei (2006), proses ARMA (p,q) adalah suatu model campuran antara autoregressive tingkat $p$ dengan model moving average tingkat $q$.

Bentuk umum dari model ini adalah:

\section{Model Subset ARIMA}

Menurut Tarno (2013), Model Subset ARIMA merupakan bagian dari model ARIMA tergeneralisasi, sehingga tidak dapat dinyatakan dalam bentuk umum. Model subset ARIMA ini merupakan himpunan bagian dari model ARIMA. Contoh model subset ARIMA ([1,5],0,[1,12]) dapat ditulis sebagai:

$$
\left(1-\phi_{1} B-\phi_{5} B^{5}\right) Z_{t}=\left(1-\theta_{1} B-\theta_{12} B^{12}\right) a_{t}
$$

dengan demikian model subset ARIMA merupakan model ARIMA dengan beberapa parameternya sama dengan nol. 


\subsubsection{Pemeriksaan Diagnostik}

\subsection{Uji White Noise Residual} Hipotesis:

Tahapan pengujian white noise adalah sebagai berikut:

$\mathrm{H}_{0} \quad: \rho_{1}=\rho_{2}=\cdots=\rho_{j}=0$ (tidak terdapat korelasi antar residual)

$\mathrm{H}_{1} \quad$ : paling sedikit terdapat satu $\rho_{k} \neq 0$, untuk $k=1,2, \ldots$, (terdapat korelasi antar residual)

Statistik uji Ljung Box:

$Q_{\text {hitung }}=n(n+2) \sum_{k=1}^{j} \frac{\hat{\rho}_{k}{ }^{2}}{(n-k)}$

dimana:

$n \quad$ : banyaknya data pengamatan

$k \quad$ : lag yang diuji dengan $k=1,2, \ldots, j$

$\rho_{k} \quad$ : dugaan Autocorrelation Function residual pada periode lag ke- $k$

j : banyaknya lag

Kriteria penolakan:

Menolak $\mathrm{H}_{0}$ jika $Q_{\text {hitung }}>\chi_{(\alpha, d f)}^{2}$ tabel, $d f$ adalah $k$ atau $\mathrm{p}$-value $<\alpha$

\subsection{Uji Normalitas Residual} Hipotesis:

Menggunakan uji Kolmogorov-Smirnov dengan tahapan sebagai berikut:

$\mathrm{H}_{0} \quad$ : Residual data berdistribusi normal

$\mathrm{H}_{1} \quad$ : Residual data tidak berdistribusi normal

Statistik Uji:

dimana:

$$
D={ }_{x}^{\sup }\left|\mathrm{S}(\mathrm{x})-\mathrm{F}_{0}(\mathrm{x})\right|
$$

$\mathrm{F}_{0}(\mathrm{x})$ : fungsi distribusi yang dihipotesiskan yaitu distribusi normal.

$\mathrm{S}(\mathrm{x}) \quad$ : fungsi distribusi sampel atau empirik.

Sup : batas atas terkecil (supremum).

Kriteria penolakan:

$\mathrm{H}_{0}$ ditolak jika $\mathrm{D}>D_{\alpha}$, atau $p$-value $<\alpha$

\subsection{Heteroskedastisitas}

Pengujian yang dapat dilakukan untuk mendeteksi keberadaan heteroskedastisitas atau keberadaan efek Autoregressive Conditional Heteroskedasticity (ARCH) adalah menggunakan Uji ARCH-Lagrange Multiplier (ARCH-LM) dengan tahapan pengujian: Hipotesis:

$\mathrm{H}_{0} \quad: \theta_{1}=\theta_{2}=\cdots=\theta_{s}=0$ (tidak ada efek ARCH)

$\mathrm{H}_{1} \quad$ : minimal ada satu nilai $\theta_{j} \neq 0$ untuk $\mathrm{j}=1,2,3, \ldots, \mathrm{s}$ (terdapat efek ARCH)

Statistik Uji:

$$
L M=\mathrm{T} R^{2}
$$

dimana $L M$ adalah Lagrange Multiplier, T adalah banyaknya observasi dan $R^{2}$ adalah koefisien determinasi model regresi dari kuadrat residual.

Kriteria penolakan:

$\mathrm{H}_{0}$ ditolak jika $L M>X_{(\alpha ; s)}^{2}$ atau p-value $<\alpha$.

\subsection{Deteksi Outlier}

Pengamatan runtun waktu kadang-kadang dipengaruhi oleh peristiwa yang tak terduga dan dapat menimbulkan pengamatan yang tidak konsisten dalam data runtun waktu atau nilainya jauh berbeda dari data lainnya. Nilai tersebut dinamakan outlier. Outlier 
menyebabkan kesimpulan dari analisis data yang dihasilkan tidak valid, sehingga prosedur yang mendeteksi dan menghapus efek outlier sangat penting dalam analisis data. Dalam time series, outlier diklasifikasikan menjadi 4 yaitu Innovational Outlier (IO), Additive Outlier (AO), Temporary Change (TC), dan Level Shift (LS). Additive Outlier (AO) hanya berpengaruh pada pengamatan ke-T, sedangkan tiga jenis outlier lainnya yaitu Innovational Outlier (IO), Level Shift (LS) dan Temporary Change (TC) berpengaruh pada pengamatan ke-T, $\mathrm{T}+1, \ldots$, dan seterusnya.

Bentuk umum sebuah Additive Outlier (AO) dalam proses ARMA diuraikan sebagai berikut:

$$
Z t=\frac{\theta(B)}{\emptyset(B)} a_{t}+\omega I_{t}^{(T)}
$$

Bentuk umum sebuah innovational outlier didefinisikan sebagai berikut:

$$
Z_{t}=X_{t}+\frac{\theta(B)}{\emptyset(B)} \omega I_{t}^{(T)}=\frac{\theta(B)}{\emptyset(B)}\left(a_{t}+\omega I_{t}^{(T)}\right)
$$

Bentuk umum model outlier LS dinyatakan sebagai:

$$
Z_{t}=X_{t}+\frac{1}{(1-B)} \omega I_{t}^{(T)}
$$

Bentuk umum model TC dapat dituliskan sebagai berikut:

$$
Z_{t}=X_{t}+\frac{1}{(1-\delta B)} \omega I_{t}^{(T)}
$$

\subsection{Evaluasi Model Peramalan}

Menurut Harahap dan Suharsono (2014), untuk data out-sample penentuan model terbaik menggunakan MAPE (Mean Absolute Percentage Error). Perhitungan MAPE untuk data out-sample adalah sebagai berikut:

$$
M A P E=\frac{1}{n} \sum_{t=1}^{n}\left|\frac{Z_{t}-\hat{Z}_{t}}{Z_{t}}\right| \times 100 \%
$$

dengan:

n : banyaknya pengamatan out-sample

$Z_{t} \quad$ : nilai data

Kemampuan peramalan dikategorikan menurut nilai MAPE sebagai berikut:

1. $<10 \% \quad$ : Kemampuan peramalan sangat baik

2. $10 \%-20 \%$ : Kemampuan peramalan baik

3. $20 \%-50 \%$ : Kemampuan peramalan cukup

4. $>50 \% \quad$ : Kemampuan peramalan buruk

\section{METODE PENELITIAN}

\subsection{Sumber Data}

Data yang digunakan dalam penulisan Tugas Akhir ini adalah data sekunder keberangkatan penumpang domestik di Bandara Internasional Soekarno-Hatta periode bulanan tahun 2011-2017 yang diperoleh dari situs resmi Badan Pusat Statistik (www.bps.go.id) sebanyak 84 data.

\subsection{Variabel Penelitian}

Variabel yang digunakan dalam penulisan Tugas Akhir adalah data bulanan kedatangan penumpang domestik di Bandara Internasional Soekarno-Hatta periode bulanan pada tahun 2011-2017 yang dijadikan variabel dependen. Sedangkan untuk variabel 
independen adalah variabel t (waktu) dan 3 variabel dummy. Variabel dummy tersebut adalah:
$\mathrm{D}_{\mathrm{t}}=\left\{\begin{array}{lc}1, & \text { bulan terjadinya Hari Raya Idul Fitri } \\ 0, & \text { yang lainnya }\end{array}\right.$
$\mathrm{D}_{\mathrm{t} 1}=\left\{\begin{array}{lc}1, & \text { satu bulan sebelum Hari Raya Idul Fitri } \\ 0, & \text { yang lainnya }\end{array}\right.$
$\mathrm{D}_{\mathrm{t} 2}=\left\{\begin{array}{lc}1, & \text { dua bulan sebelum Hari Raya Idul Fitri } \\ 0, & \text { yang lainnya }\end{array}\right.$

\subsection{Langkah-langkah Analisis}

Langkah-langkah analisis yang dilakukan dalam menyelesaikan Tugas Akhir ini adalah sebagai berikut:

1. Membagi data menjadi dua bagian, yaitu data in-sample dan data out-sample.

2. Data out-sample yang digunakan untuk menentukan tingkat ketepatan model variasi kalender dengan deteksi outlier.

3. Melakukan identifikasi model.

4. Menghilangkan efek variasi kalender dari variabel respons dengan menggunakan model regresi dummy.

5. Melakukan uji white noise pada residual dummy dengan melihat plot ACF residual dummy.

6. Melakukan uji stasioneritas dalam mean dan varian.

7. Melakukan pengujian model ARIMA yang diperoleh pada langkah ketiga digunakan untuk memodelkan data jumlah kedatangan penumpang domestik di Bandara Internasional Soekarno-Hatta serta variabel dummy pada variasi kalender.

8. Melakukan uji signifikansi parameter menggunakan uji $t$.

9. Melakukan uji asumsi residual yaitu memenuhi asumsi residual white noise, asumsi residual berdistribusi normal, dan uji heteroskedastisitas.

10. Pemilihan model terbaik berdasarkan nilai AIC terkecil.

11. Melakukan pendeteksian outlier pada model terbaik yang telah diperoleh.

12. Melakukan pemodelan dengan memasukkan outlier.

13. Melakukan evaluasi model peramalan menggunakan MAPE.

14. Melakukan peramalan (forecasting).

\section{HASIL DAN PEMBAHASAN}

\subsection{Regresi Dummy}

Dilihat dari sebaran data menggunakan time series plot untuk mengidentifikasi model dugaan yang sesuai. Pola data penelitian adalah sebagai berikut:

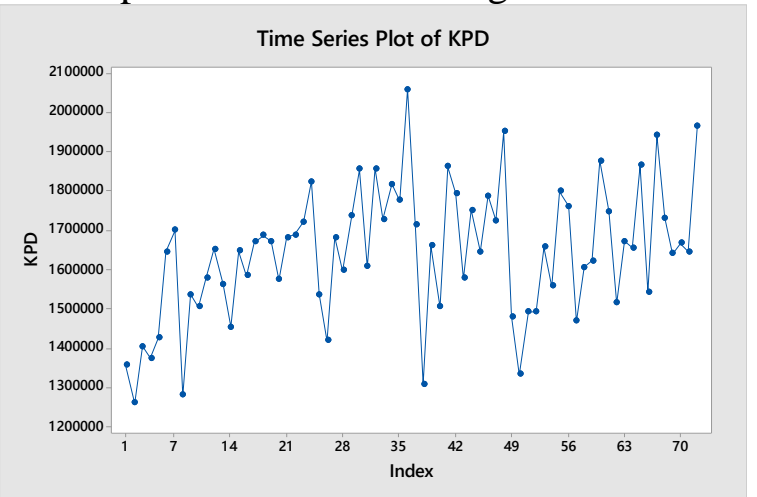

Gambar 1. Time Series Plot KPD di Bandara Internasional Soekarno-Hatta 
Gambar 1 menunjukkan bahwa pola data KPD mempunyai kecenderungan meningkat dengan lonjakan peningkatan kedatangan penumpang pada bulan-bulan tertentu yang ditengarai sebagai lonjakan kedatangan penumpang pada hari raya Idul Fitri, pada sebelum ataupun sesudah hari raya Idul Fitri. Oleh karena itu, diduga model regresi untuk data jumlah KPD di Bandara Internasional Soekarno-Hatta adalah sebagai berikut:

$$
Z_{t}=\beta_{0}+\beta_{1} t+\beta_{2} D_{t}+\beta_{3} D_{t 1}+\beta_{4} D_{t 2}+\varepsilon_{t}
$$

Terdapat empat kriteria variabel dummy, yaitu t menunjukkan periode data, $D_{t}$ menunjukkan bulan terjadinya hari raya, $D_{t 1}$ menunjukkan satu bulan sebelum hari raya terjadi, $D_{t 2}$ menunjukkan dua bulan sebelum hari raya terjadi.

Langkah selanjutnya setelah terbentuk model regresi dummy, dilakukan pengujian signifikansi parameter yang dilakukan secara bersama-sama (serentak) dan secara parsial dengan eliminasi backward. Didapatkan hasil sebagai berikut:

Dari Tabel 1 dilihat bahwa parameter $\beta_{0}, \beta_{1}$, dan $\beta_{4}$ merupakab parameter yang signifikan terhadap model.

Tabel 1. Nilai Signifikansi Parameter Uji Parsial dan Uji Serentak

\begin{tabular}{|c|c|c|c|c|}
\hline Parameter & Koefisien & $\begin{array}{l}\text { p-value ( uji } \\
\text { parsial ) }\end{array}$ & $\begin{array}{l}\text { p-value ( uji } \\
\text { serentak ) }\end{array}$ & Keputusan \\
\hline$\beta_{0}$ & 1517564 & 0,000 & & $\mathrm{H}_{0}$ ditolak \\
\hline$\beta_{1}$ & 3049 & 0,001 & 0,001 & $\mathrm{H}_{0}$ ditolak \\
\hline$\beta_{4}$ & 134899 & 0,043 & & $\mathrm{H}_{0}$ ditolak \\
\hline
\end{tabular}

Langkah selanjutnya adalah menguji asumsi white noise untuk residual dari model tersebut harus memenuhi asumsi white noise, karena jika asumsi ini tidak terpenuhi maka dilakukan pemodelan residual dummy menggunakan model ARIMA.

Hasil uji menunjukkan bahwa KPD tidak memenuhi asumsi white noise. Oleh karena itu, KPD perlu dimodelkan dengan model ARIMAX yaitu ARIMA dengan penambahan variabel dummy.

\subsection{Uji Stasioneritas}

\subsubsection{Uji Stasioneritas dalam Varian}

Analisis stasioneritas dalam varian dilakukan uji Box-Cox dengan melihat plot BoxCox. Nilai lambda $(\lambda)$ yang didapatkan sebesar 0,5 . Hal ini berarti asumsi stasionerias varian data KPD tidak stasioner sehingga diperlukan transformasi data $\sqrt{ } \mathrm{Z}_{\mathrm{t}}$.

Setelah dilakukan transformasi maka perlu dikembali dilakukan regresi antara data transformasi dan variable dummy yang ada, diperoleh model baru:

$$
\widehat{Z}_{t}=1230,6+1,205 t+53 D_{t 2}
$$

Kembali dilakukan uji Box-Cox dan mendapat Nilai lambda $(\lambda)$ yang didapatkan sebesar 1.

\subsubsection{Uji Stasioneritas dalam Mean}

Untuk mengetahui apakah data stasioner dalam mean, dilakukan uji Augmented Dickey-Fuller. Dengan menggunakan software E-views didapatkan probabilitas uji Augmented Dickey-Fuller didapatkan nilai p-value yang didapat lebih kecil dari $\alpha=0,05$ sehingga data telah stasioner dalam mean.

\subsection{Permodelan Sementara}

Setelah stasioneritas data dalam mean dan varian (ragam) terpenuhi, maka dilakukan pemodelan sementara dengan melihat plot ACF dan PACF dari residual data yang dapat dilihat pada gambar berikut: 


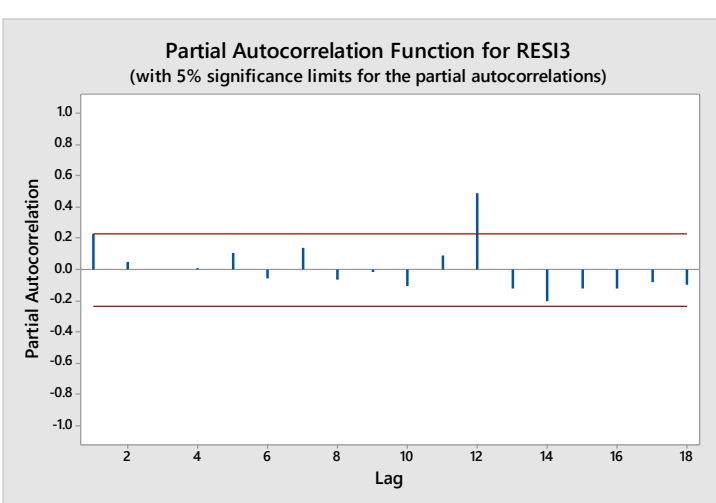

Gambar 2. Plot PACF Residual KPD

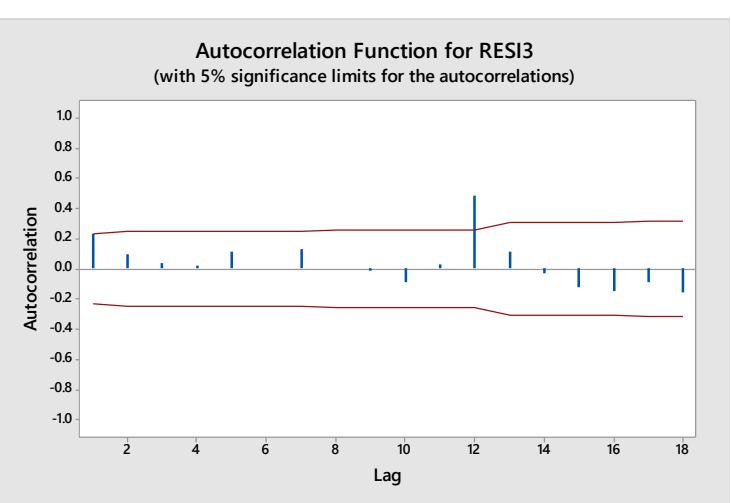

Gambar 3. Plot ACF Residual KPD

Pendugaan orde AR ditentukan melalui plot PACF yang terbentuk. Pada Gambar 12 menunjukkan pola terputus pada lag ke-1 dan 12. Sedangkan untuk pendugaan orde MA ditentukan melalui plot ACF yang terlihat pada Gambar 13, pola terputus pada lag ke-1 dan 12. Sehingga terdapat 15 kemungkinan model ARIMA yang terbentuk, yaitu: ARIMA $(1,0,0)$, ARIMA ([12],0,0), ARIMA ([1,12],0,0), ARIMA $(0,0,1)$, ARIMA $(0,0,[12])$, ARIMA $(0,0,[1,12])$, ARIMA $(1,0,1)$, ARIMA $(1,0,[12])$, ARIMA $(1,0,[1,12])$, ARIMA ([12],0,1), ARIMA ([12],0,[12]), ARIMA ([12],0,[1,12]), ARIMA ([1,12],0,1), ARIMA $([1,12], 0,[12])$, dan ARIMA $([1,12], 0,[1,12])$

\subsection{Uji Signifikansi Parameter}

Pada taraf signifikansi 5\%, dari 15 dugaan model terdapat 4 model yang seluruh parameternya signifikan, yaitu: ARIMA $(1,0,0), \mathrm{t}, D_{t 2}$, ARIMA $([1,12], 0,0)$, $\mathrm{t}, D_{t 2}, \operatorname{ARIMA}(0,0,[12]), \mathrm{t}, D_{t 2}$, ARIMA $(1,0,[12]), \mathrm{t}, D_{t 2}$.

\subsection{Uji Asumsi Residual White Noise}

Berdasarkan hasil uji white noise menunjukkan bahwa hanya model ARIMA $(1,0,[12])$ memenuhi asumsi white noise .

\subsection{Uji Homokedastisitas Residual} ada efek ARCH.

Dilakukan dengan uji LM atau Lagrange Multiplier model ARIMA $(1,0,[12])$ tidak

\subsection{Uji Asumsi Distribusi Normal}

Uji asumsi distribusi normal menggunakan uji Kolmogorov-Smirnov. Pada taraf signifikansi 0,05 model ARIMA $(1,0,[12]), \mathrm{t}, D_{t 2}$ memiliki nilai $p$-value $=0,0793$, sehingga $\mathrm{H}_{0}$ diterima. Maka residual data memiliki distribusi normal.

\subsection{Model Terbaik}

Model ARIMA $(1,0,[12])$, t, $D_{t 2}$ adalah model terbaik dan sesuai untuk digunakan sebagai model peramalan. Sehingga model yang terbentuk adalah:

\subsection{Deteksi Outlier}

Didapatkan hanya satu outlier pada data ke-49 yang bertipe Additive Outlier(AO). Selanjutnya dilakukan estimasi parameter untuk model ARIMA $(1,0,[12]), \mathrm{t}, D_{t 2}$ dengan menambahkan outlier tersebut apakah akan memenuhi signifikansi parameter dan juga asumsi residual model: white noise residual, normalitas residual, dan homokedastisitas residual. 
Berdasarkan analisis bahwa model ARIMA $(1,0,[12]), \mathrm{t}, D_{t 2}$ dengan penambahan outlier pada data ke-49 merupakan model terbaik dan akan digunakan untuk melakukan peramalan. Sehingga model akhir untuk model variasi kalender dengan deteksi outlier adalah sebagai berikut:

$$
\widehat{Z}_{t}=1192,3+2,06325 t+67,16292 D_{t 2}+\frac{\left(1+0,70191 B^{12}\right)}{\left(1-0,34565 B^{1}\right)} a_{t}-110,06173 I_{t}^{(49)}
$$

\subsection{Penentuan Nilai MAPE}

Nilai MAPE yang diperoleh sebesar 7,04\% membuktikan bahwa ketepatan peramalan model ARIMA $(1,0,[12]), \mathrm{t}, D_{t 2}$ sangat baik, sehingga baik untuk digunakan meramal KPD di Bandara Soekarno Hatta periode selanjutnya.

\subsection{Peramalan}

Hasil prediksi jumlah KPD di Bandara Internasional Soekarno-Hatta untuk periode Januari tahun 2018 hingga Desember tahun 2020 adalah sebagai berikut:

\section{Tabel 4. Prediksi KPD}

\begin{tabular}{|c|c|c|c|c|c|}
\hline $\mathrm{T}$ & Waktu & Peramalan & $\mathrm{T}$ & Waktu & Peramalan \\
\hline 85 & Januari 2018 & 1891387 & 103 & Juli 2019 & 1973541 \\
\hline 86 & Februari 2018 & 1883413 & 104 & Agustus 2019 & 1979342 \\
\hline 87 & Maret 2018 & 1884366 & 105 & September 2019 & 1985152 \\
\hline 88 & April 2018 & 2077505 & 106 & Oktober 2019 & 1990970 \\
\hline 89 & Mei 2018 & 1893515 & 107 & November 2019 & 1996797 \\
\hline 90 & Juni 2018 & 1899002 & 108 & Desember 2019 & 2002632 \\
\hline 91 & Juli 2018 & 1904625 & 109 & Januari 2020 & 2008476 \\
\hline 92 & Agustus 2018 & 1910301 & 110 & Februari 2020 & 2014328 \\
\hline 93 & September 2018 & 1916000 & 111 & Maret 2020 & 2215622 \\
\hline 94 & Oktober 2018 & 1921714 & 112 & April 2020 & 2026058 \\
\hline 95 & November 2018 & 1927437 & 113 & Mei 2020 & 2031936 \\
\hline 96 & Desember 2018 & 1933170 & 114 & Juni 2020 & 2037823 \\
\hline 97 & Januari 2019 & 1938912 & 115 & Juli 2020 & 2043718 \\
\hline 98 & Februari 2019 & 1944662 & 116 & Agustus 2020 & 2049621 \\
\hline 99 & Maret 2019 & 1950421 & 117 & September 2020 & 2055533 \\
\hline 100 & April 2019 & 2148572 & 118 & Oktober 2020 & 2061454 \\
\hline 101 & Mei 2019 & 1961964 & 119 & November 2020 & 2067382 \\
\hline 102 & Juni 2019 & 1967748 & 120 & Desember 2020 & 2073320 \\
\hline
\end{tabular}


Berdasarkan Tabel 15 diketahui jumlah KPD terbanyak di Bandara Internasional Soekarno-Hatta terjadi pada dua bulan sebelum Idul Fitri tiap tahunnya, yaitu pada bulan April 2018, April 2019, dan Maret 2020.

\section{KESIMPULAN}

Berdasarkan analisis dan pembahasan yang telah dilakukan maka dapat diambil kesimpulan sebagai berikut:

1. Model yang terbaik dari metode variasi kalender adalah model ARIMA $(1,0,[12])$, $\mathrm{t}, D_{t 2}$ dengan penambahan satu outlier.

2. Prediksi jumlah KPD menunjukkan pada penumpang terbanyak di Bandara Internasional Soekarno-Hatta terjadi pada dua bulan sebelum Idul Fitri tiap tahunnya, yaitu pada bulan April 2018, April 2019, dan Maret 2020.

\section{DAFTAR PUSTAKA}

Afriani,I., et al. 2013. Pemodelan dan Peramalan Jumlah Pengunjung KBS Menggunakan Model Variasi Kalender ARIMAX. Statistika, FMIPA, Institut Teknologi Sepuluh Nopember Surabaya.

Ariefianto, M.D. 2012. Ekonometrika Esensi dan Aplikasi dengan Menggunakan Eviews. Edisi 4. Yogyakarta: UPP, STIM YPKN.

Bell, W.R. dan Hilmer, S. 1983. Modelling Time Series with Calendar Variation, Journal of American Statistical Association.

Bowerman, B. L., O' Connell, R. T., dan Emily M. 2012. Bussiness Statistics in Practice. New York: McGraw-Hill.

Damardjati, R.S. 1995. Istilah-istilah Dunia Pariwisata. Jakarta: PT. Pradnya Paramitha.

Dini,N.S., Haryono, dan Suhartono. 2012. Peramalan Kebutuhan Premium dengan Metode ARIMAX untuk Optimasi Persediaan di Wilayah TBBM Madiun. Jurusan Statistika, Fakultas Matematika dan Ilmu Pengetahuan Alam, Institut Teknologi Sepuluh Nopember (ITS)

Engle, R.F. 1982. Autoregressive Conditional Heteroscedasticity with Estimates of the Variance of United Kingdom Inflation. Econometrica, Vol. 50, No. 4. (Jul., 1982), pp. 987-1007.

Filzmoser,P., R. Maronna, and M. Werner. 2006. Outlier identification in high dimensions. Gujarati, D.N.. 1978. Ekonometrika Dasar. Jakarta: Erlangga.

Gujarati, D.N. 2004. Basic Econometrics (Ekonometrika Dasar). Alih Bahasa Sumarno Zain. Jakarta: Penerbit Erlangga.

Gujarati, D. N. 2013. Dasar-dasar Ekonometrika, Edisi Kelima. Mangunsong, R. C. penerjemah. Jakarta: Salemba Empat.

Halimi,R., Anggaeni, W., dan Tyasnurita, R. 2013. Pembuatan Aplikasi Peramalan Jumlah Permintaan Produk Dengan Metode Time Series Exponential Smoothing Holts Winter di PT. Telekomunikasi Indonesia Tbk. Jurnal Teknik POMITS Vol. I, No. 1, Hal: 1-6

Harahap, M.R.P dan Suharsono, A. 2014. Analisis Peramalan Penjualan Sepeda Motor di Kabupaten Ngawi dengan Arima dan Arimax. Jurnal Sains dan seni POMITS 3(2):122-126.

Izza,M.L. Destri S., dan Suhartono. 2014. Peramalan Penjualan Sepeda Motor Menurut Tipe Dengan Pendekatan Autoregressive Integrated Moving Average With Exogeneous Input (Arimax) Di Kabupaten Banyuwangi. Jurusan Statistika, Fakultas Matematika dan Ilmu Pengetahuan Alam, Institut Teknologi Sepuluh Nopember (ITS) 
Liu,L.M. 1986. Identification of Time Series Models in Presence of Calendar Variation. International journal and Forecasting, Vol. 2, No. 3, 357-372.

Makridakis, S, Wheelwright, S.C, McGee, V.E. 1999. Metode dan Aplikasi Peramalan. Jilid I. Edisi 2. Jakarta: Erlangga.

Ristianti A., Erna H., Nunun H. M. 2014. Peramalan Permintaan Pengujian Sampel Di Laboratorium Kimia Dan Fisika Baristand Industri Surabaya.

Rosadi, D. 2012. Ekonometrika \& Analisis Runtun Waktu Terapan dengan Eviews. Yogyakarta. Penerbit ANDI.

Soejoeti, Z. 1987. Analisis Runtun Waktu, Materi Pokok UT. Jakarta. Karunika.

Subagyo, P. 1986. Forecasting Konsep dan aplikasi .Yogyakarta: BPPE UGM.

Suhartono, Lee, M.H, dan Hamzah, N.A. 2010. Calendar Variation Model Based on ARIMAX for Forecasting Sales Data with Ramadhan Effect. Proceedings of the Regional Conference on Statistical Sciences. 349-361. Malaysia Institute of Mathematical Sciences University of Malaya.

Suryaningtyas, W. 2011. Peramalan Volume Penjualan Celana Panjang di Boyolali dengan Menggunakan Model Variasi Kalender. Yogyakarta. Prosiding Seminar Nasional dan Pendidikan Matematika FMIPA UNY.

Suryawati, G., dan Suyitno. 2012. Model Variasi Kalender untuk Peramalan Volume Penjualan Tiket Penumpang Speedboat di Dermaga Kampung Baru Balikpapan. Program Studi Statistika FMIPA Universitas Mulawarman

Tarno. 2013. Kombinasi Prosedur Pemodelan Subset Arima dan Deteksi Outlier untuk Prediksi Data Runtun Waktu. Prosiding Seminar Nasional Statistika UNDIP 2013. Semarang.

Wei, W.W.S. 2006. Time Series Analysis, Univariate and Multivariate Methods. Canada. Addison Wesley Publishing Company. 